\title{
Numerical Calculation of Secondary Flow in Pump Volute and Circular Casings using 3D Viscous Flow Techniques
}

\author{
K. MAJIDI ${ }^{\mathrm{a}, *}$ and H.E. SIEKMANN ${ }^{\mathrm{b}}$ \\ ${ }^{a}$ Dr.-Ing., Institut für Verbrennungskraftmaschinen, Technische Universität Berlin, Carnotstrasse. Ia \\ D-10587 Berlin, Germany; ${ }^{\mathrm{b}}$ Prof. Dr.-Ing., Institut für Hydraulische Strömungsmaschinen und Strömungstechnik \\ Technische Universität Berlin, Straße des 17. Juni 135, D-10623 Berlin, Germany
}

(Received in final form 17 September 1998)

\begin{abstract}
The flow field in volute and circular casings interacting with a centrifugal impeller is obtained by numerical analysis. In the present study, effects of the volute and circular casings on the flow pattern have been investigated by successively combining a volute casing and a circular casing with a single centrifugal impeller. The numerical calculations are carried out with a multiple frame of reference to predict the flow field inside the entire impeller and casings. The impeller flow field is solved in a rotating frame and the flow field in the casings in a stationary frame. The static pressure and velocity in the casing and impeller, and the static pressures and secondary velocity vectors at several cross-sectional planes of the casings are calculated. The calculations show that the curvature of the casings creates pressure gradients that cause vortices at cross-sectional planes of the casings.
\end{abstract}

Keywords: Volute casing, Circular casing, Secondary flow, Centrifugal impeller, CFD

\section{INTRODUCTION}

The three dimensional flow pattern inside the volute and circular casings of centrifugal pumps are strongly influenced by secondary flows that are created by the curvature of the casing passages. The flow pattern in casings also affects the performance of the pump.

In recent years improved computational algorithms and hardware development have contributed to enhance CFD capability. It is now feasible to use CFD codes for a realistic prediction of the complex 3D turbulent flow in the entire pump. The objective of this study is to investigate the secondary flow in volute and circular casings of centrifugal pumps. Several numerical calculations are carried out with a multiple frame of reference to predict the flow pattern inside the entire impeller and casing, whereby the impeller flow field is solved in a rotating frame, and the casing in a fixed one. The two frames of reference are connected in such a way that they each have a fixed relative position

*Corresponding author. Tel.: +49 30/31426107. Fax: +49 30/31426105. E-mail: Kitano.Majidi@Tu-Berlin.DE. 
throughout the calculation. The appropriate transformation occurs across a sliding interface without any interface averaging. This approach accounts for interaction between the two frames. The present calculations are done using a commercially available software package TASCflow (1995).

\section{IMPELLER AND CASING GEOMETRY AND TEST CONDITIONS}

The impeller employed in this analysis is a commercial one with axial inlet and radial outlet and was designed to operate at the following design point:

$$
\begin{array}{ll}
\text { Mass flow rate } & \dot{m}_{\mathrm{opt}}=730.0 \mathrm{~kg} / \mathrm{s}, \\
\text { Head } & H=46.68 \mathrm{~m}, \\
\text { Speed } & n=1482 \mathrm{rpm} .
\end{array}
$$

The impeller is shrouded and has five backswept blades. The blade profile varies between the hub and the shroud. The blade angle at the inlet varies from $18.5^{\circ}$ (from tangential) at the shroud to $30.0^{\circ}$ at the hub. The blade angle at the outlet is $23.5^{\circ}$. At the outlet the impeller has a diameter of $d_{2}=508 \mathrm{~mm}$ and a width of $b_{2}=72.5 \mathrm{~mm}$. The shape of the single volute casing is derived on the basis of the theory of a constant average velocity for all sections of the volute, according to Stepanoff (1949). This means that volute areas increase proportionally to their angular advancement from the volute tongue. The volute has a width of $b_{3}=94.3 \mathrm{~mm}$ and a base circle with a diameter of $d_{3}=538 \mathrm{~mm}$. Three volute area geometries having different opening angles of casing side walls $\theta=30^{\circ}, 50^{\circ}$ and $70^{\circ}$ were examined in these studies. The circular casing is of a constant axial depth of $b=217.5 \mathrm{~mm}$ throughout and has a diameter of $d_{4}=700 \mathrm{~mm}$.

\section{COMPUTATIONAL METHOD}

\subsection{Governing Equations and Numerical Scheme}

The flow solver of the CFD code employs for incompressible turbulent flow the continuity equation and the 3D time-averaged Navier-Stokes equations (Reynolds equations). The eddy viscosity assumption is used to model the Reynolds stresses. The turbulent viscosity is determined by means of the standard $k-\varepsilon$ turbulence model. The walls are modeled using a log-law wall function. The transport equations are discretized using the conservative finite volume method. For the present study the advection terms in the integral equations are modeled employing a second order accurate skewed upwind differencing scheme with physical advection correction. The software is well documented.

\subsection{Computational Domain, Grid Generation and Boundary Conditions}

The grid of the impeller models all impeller blades and passages, and has a total of 55860 nodes, as shown in Fig. 1. The grids of the volute and the

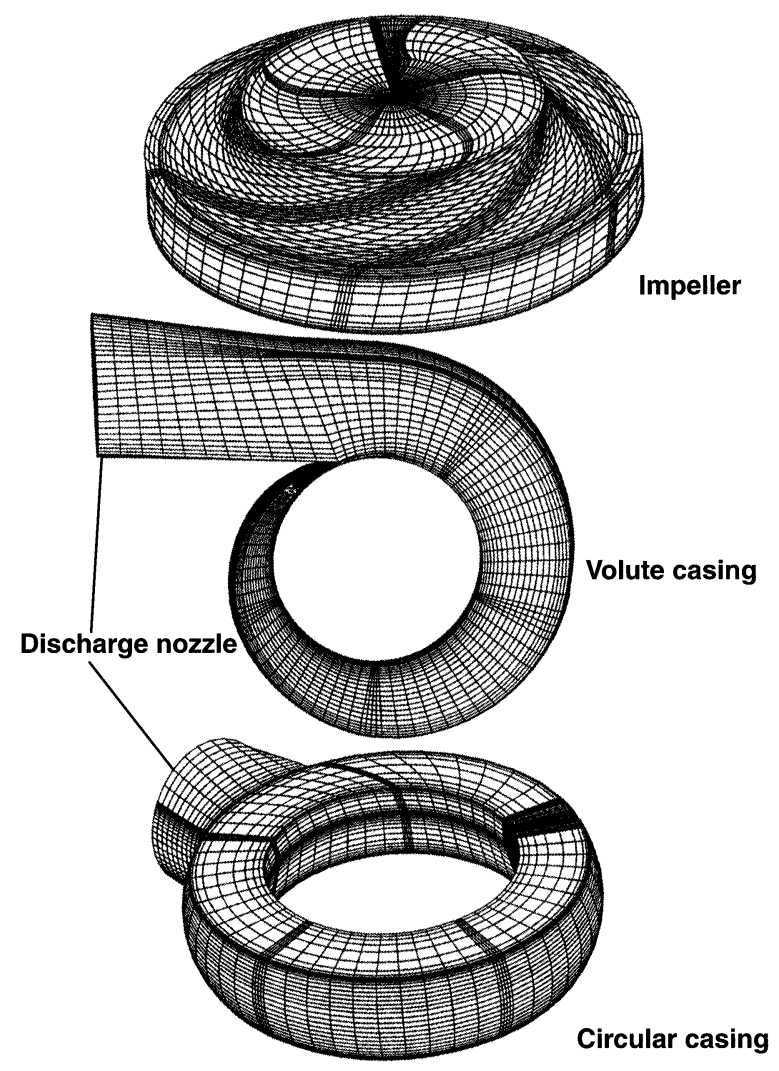

FIGURE 1 Grids of the computational domains. 
circular casings were both generated in two blocks (one for the casing and one for the discharge nozzle) for a total of 57816 nodes for volute casing and 34317 nodes for the circular casing, Fig. 1.

At the inlet of the computational domain, the mass flow rate in the absolute frame of reference, turbulence intensity, length scale and the reference pressure at one grid point are specified. The inlet velocity vector is in the axial direction. The blades, hub and shroud surfaces and casings surfaces are modeled as solid walls. All periodic grid surfaces are defined as periodic boundary conditions. The fluid variables are extrapolated at the outlet of the discharge nozzle sectional plane. The grids of the impeller and the casing are connected by means of a sliding interface. The sliding interface is a frozen rotor interface. It means the reference change occurs as the flow crosses the interface without imposing any circumferential averaging. The two components remain fixed for the entire simulation.

\section{RESULTS}

The entire three-dimensional quasi-steady flow field in the centrifugal impeller, volute and circular casings, is obtained by numerical analysis. The fringed contours of static pressure and velocity distributions at midspan of the impeller and volute casings at the design point are shown in Figs. 2 and 3, respectively. According to Fig. 2 the static pressure distribution shows some negligible circumferential nonuniformity at the impeller outlet. This effect results in the well-known radial thrust which is normally zero at best efficiency point for low

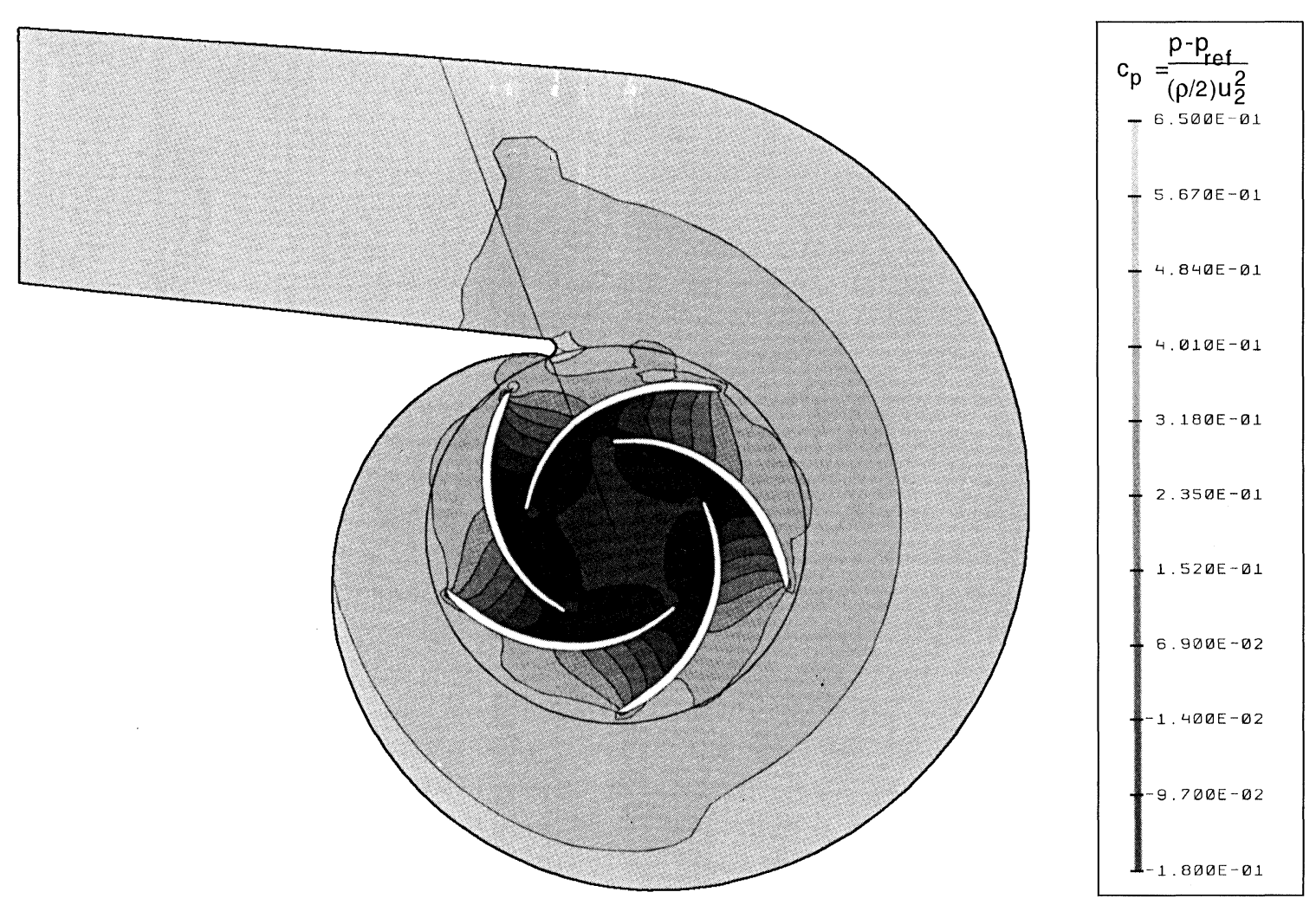

FIGURE 2 Pressure distribution at the midspan of the impeller and volute casing of the centrifugal pump at the design point. 


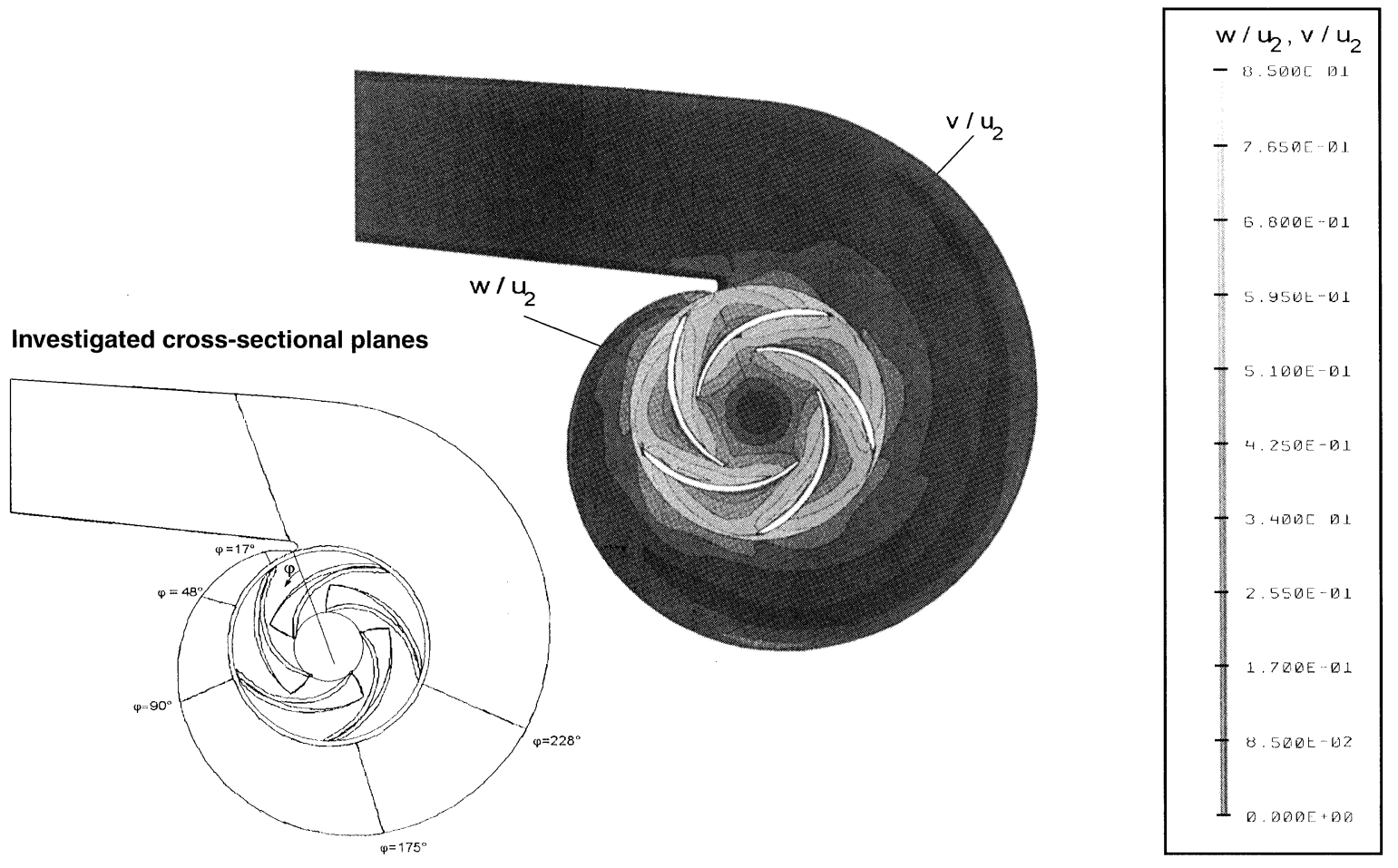

FIGURE 3 Velocity distribution at the midspan of the impeller and volute casing of the centrifugal pump at the design point.

specific speeds and for higher specific speeds very small. As shown in Fig. 3, the maximum relative velocity is at the impeller periphery. At some regions of the volute casing the absolute velocities are very low. These regions are the center of vortices in the casing (see Fig. 4). The secondary flow at the volute casing is investigated at different crosssectional planes by different angular advancements $\varphi$ from the volute tongue, shown at the lower part of Fig. 3. The secondary velocity vectors arising from the passage curvature (centrifugal forces) and boundary layers are identified in Fig. 4. These vectors are the projections of the calculated velocity vectors onto the investigated cross-sectional planes. As depicted in Fig. 4 the high velocity core in the volute is driven by the impeller. Radial outward orientated components of the absolute velocity exist at the shroud side and inward orientated components exist at the hub side of the volute walls. As a parameter, the opening angle $\theta$ of the volute side walls was varied. The results of the calculated secondary velocity vectors at two different angular advancements are shown in Figs. 5 and 6 . Figure 5 shows for $\varphi=48^{\circ}$ at $\theta=30^{\circ}$ nearly the same secondary vectors as in Fig. 4 for the same $\varphi$ - and $\theta$-values, although the mass flow is slightly different (in Fig. $5 \dot{m} / \dot{m}_{\text {opt }}=0.93$ ). Figure 6 also represents the pressure distribution at the crosssectional plane at $\varphi=273^{\circ}$. According to this figure, there exist large radial pressure gradients in the volute. These pressure gradients effect radial velocities and reverse them near the side walls. The fringed contours of static pressure and velocity distributions at midspan of the impeller and circular 


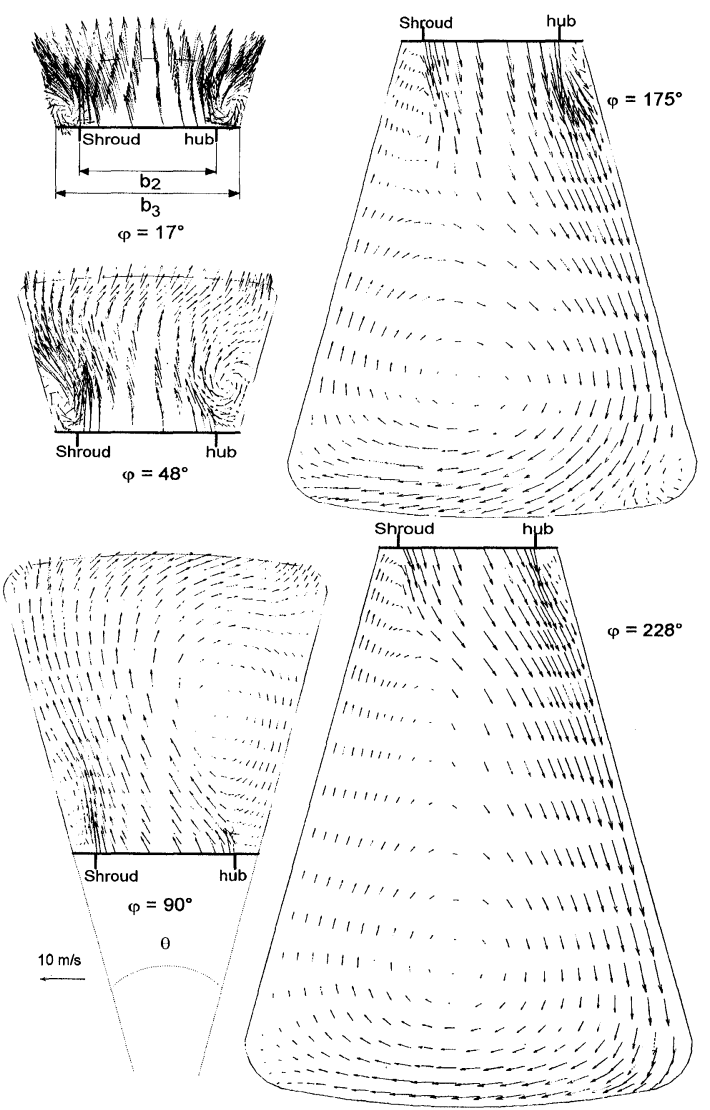

FIGURE 4 Secondary flow at different cross-sectional planes (Fig. 3) of the volute casing with an opening angle of casing side walls of $\theta=30^{\circ}$ at angular advancements of $\varphi=17^{\circ}, 48^{\circ}, 90^{\circ}, 175^{\circ}$ and $228^{\circ}$ at the design point.

casings at the design point are shown in Fig. 7. As in the volute casing, the flow at the impeller periphery does not have a uniform static pressure distribution. The nonuniformity is even more dominant. The flow in the circular casing is split into two parts. The first part, which can be observed at low angular advancements, is inactive, and circulates in the casing. The second part is active, and carries the impeller mass flow out through the discharge nozzle. This part forms a nearly volute body of liquid inside the casing (Stepanoff, 1949). Figure 8 shows the secondary velocity vectors and pressure distribution at a circular casing
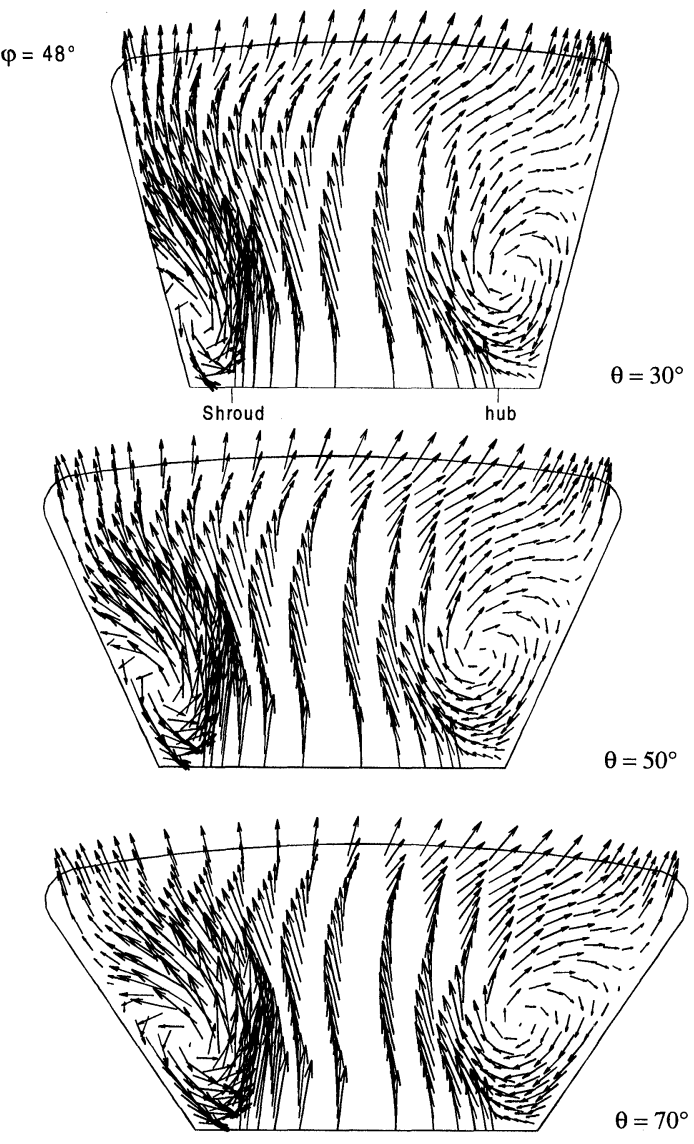

FIGURE 5 Influence of geometry of the volute area on secondary flow at an angular advancement of $\varphi=48^{\circ}$ at $\dot{m}=676.3 \mathrm{~kg} / \mathrm{s}\left(\dot{m} / \dot{m}_{\mathrm{opt}}=0.93\right)$.

cross-sectional plane with an angular advancement of $\varphi=88^{\circ}$.

\section{CONCLUSION}

The results obtained show that the flow in the volute and circular casing of centrifugal pumps are highly three-dimensional. The presence of strong secondary flows in the casings was confirmed. The results indicate that reliable CFD codes for 3D viscous flow analysis are very powerful instruments to improve our understanding of the extremely 


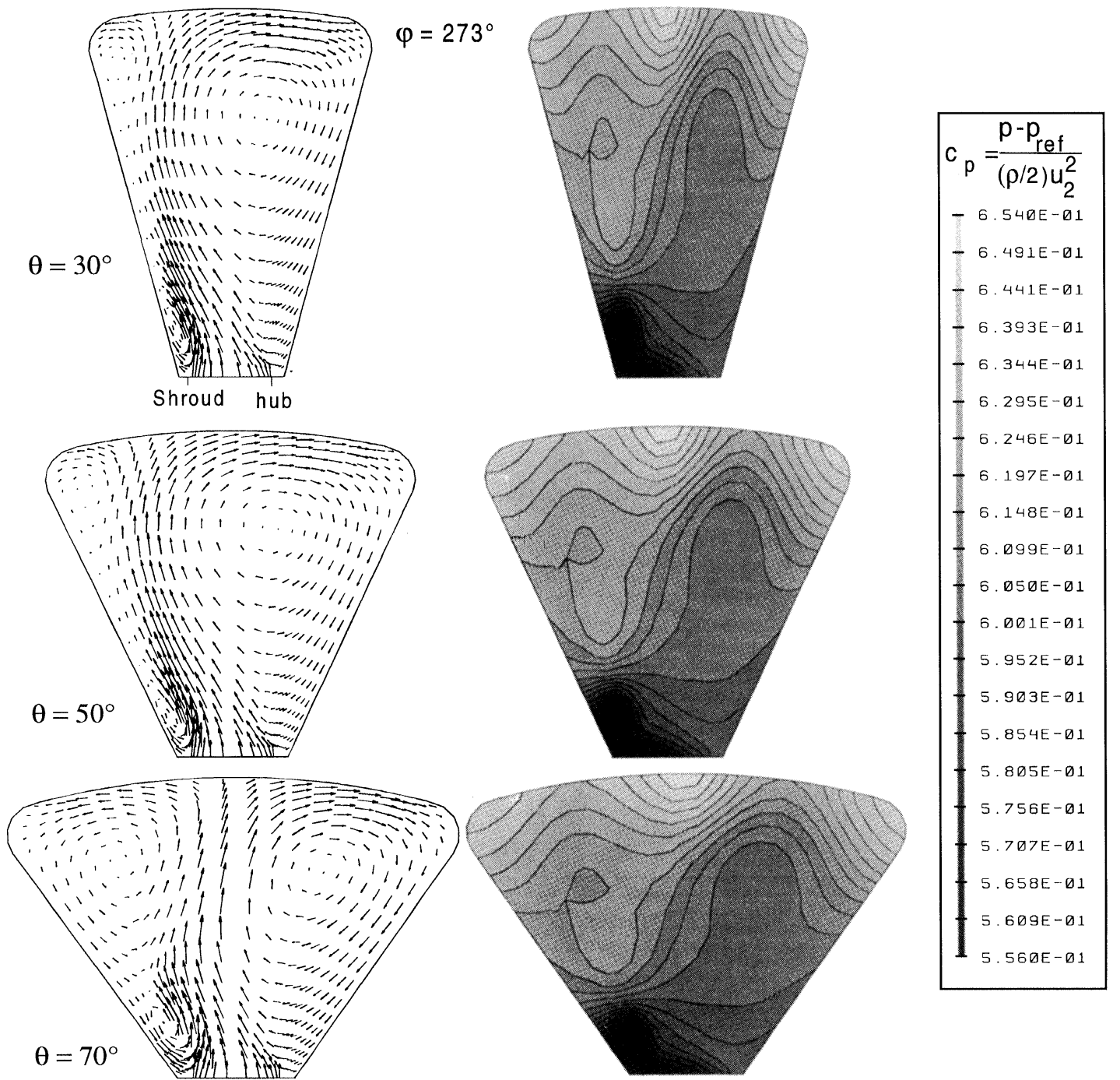

FIGURE 6 Influence of geometry of the volute area on secondary flow and pressure distribution in the cross-sectional plane of the volute at an angular advancement of $\varphi=273^{\circ}$ at $\dot{m}=676.3 \mathrm{~kg} / \mathrm{s}\left(\dot{m} / \dot{m}_{\mathrm{opt}}=0.93\right)$.

complex internal flows in turbomachines. The results provide insights into the development of secondary flows in casings of centrifugal pumps under the influence of centrifugal forces caused by passage curvature.

\section{NOMENCLATURE}

$b \quad$ width of circular casing (mm)

$b_{2}$ impeller width (mm) $b_{3}$ volute width $(\mathrm{mm})$

$c_{p}$ pressure coefficient

$d_{2}$ impeller outlet diameter ( $\left.\mathrm{mm}\right)$

$d_{3}$ diameter of volute base circle $(\mathrm{mm})$

$d_{4}$ diameter of circular casing $(\mathrm{mm})$

$H \quad \operatorname{Head}(\mathrm{m})$

$\dot{m}$ mass flow rate $(\mathrm{kg} / \mathrm{s})$

$n \quad$ rotating speed $\left(\mathrm{min}^{-1}\right)$

$p \quad$ static pressure $(\mathrm{Pa})$

$u_{2}$ circumferential speed $(\mathrm{m} / \mathrm{s})$ 


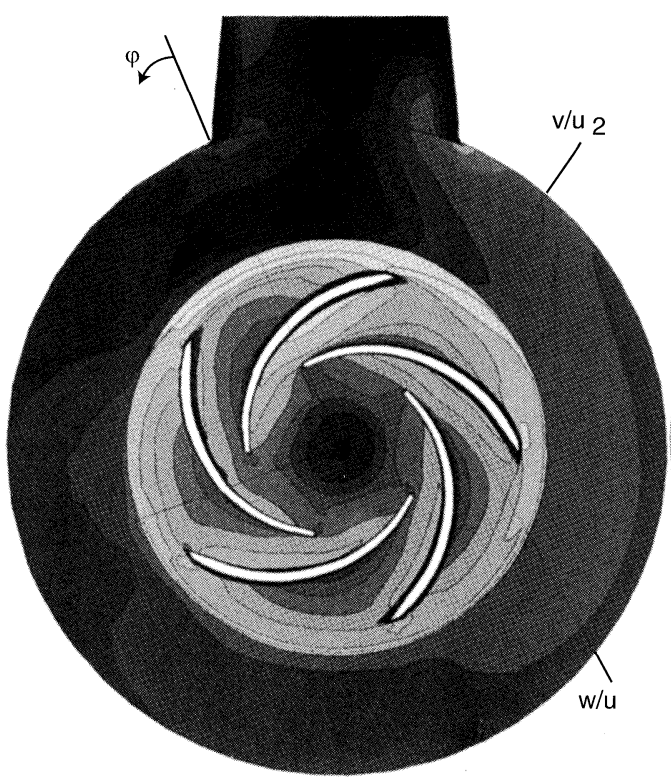

Velocity distribution (for velocity scale see fig. 3 )

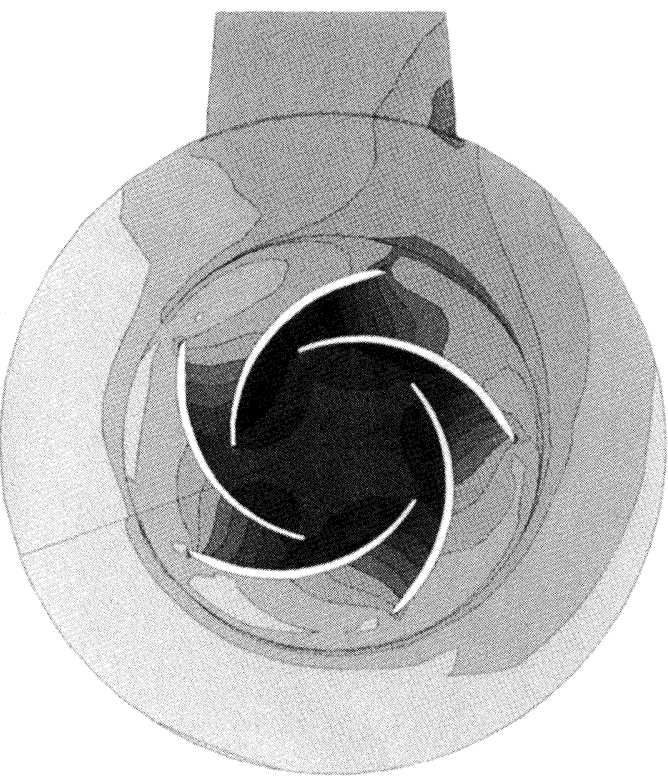

Pressure distribution

(for pressure scale see fig. 2)

FIGURE 7 Pressure and velocity distribution at the midspan of the impeller and in the circular casing at the design point.

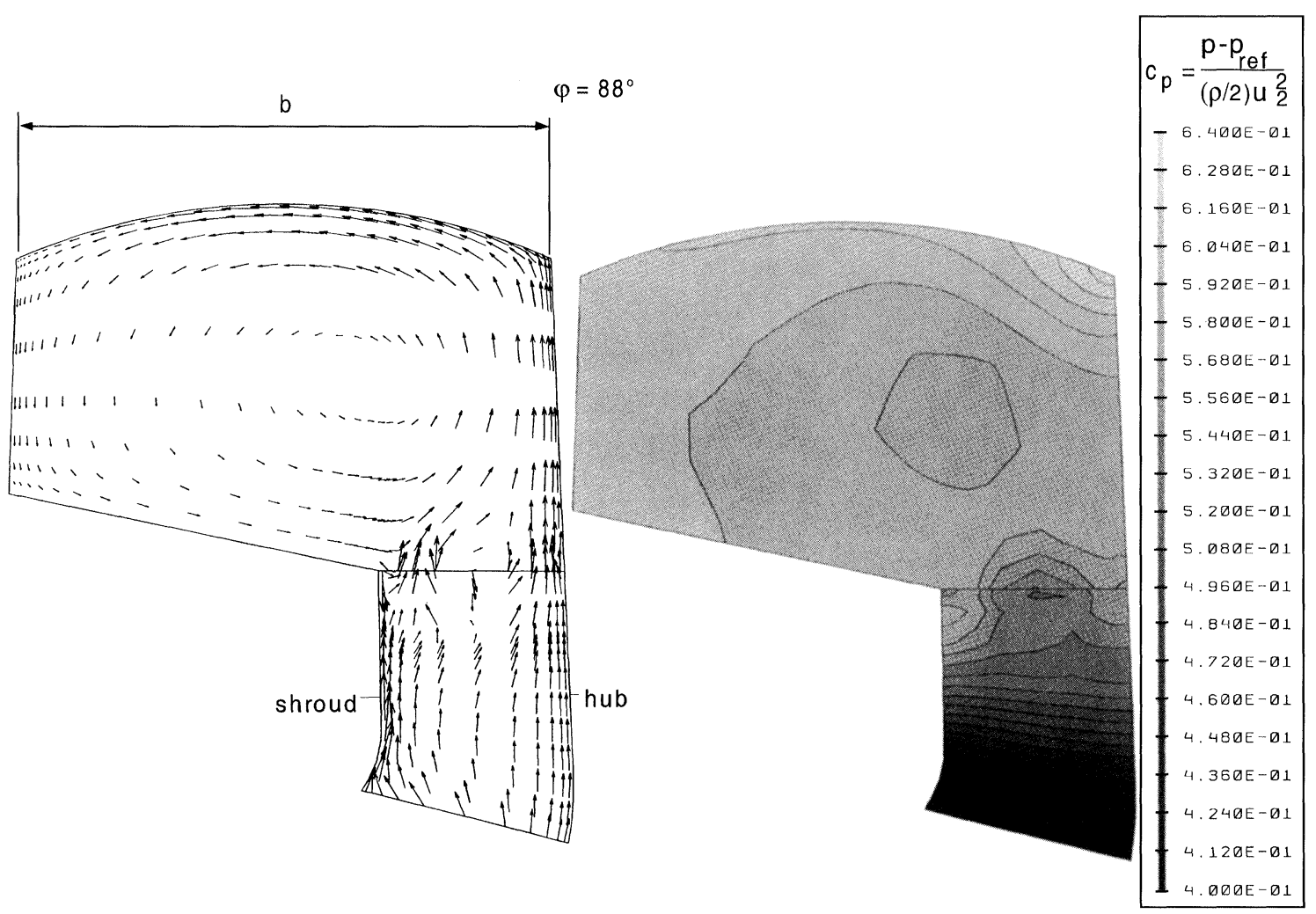

FIGURE 8 Secondary flow and pressure distribution at the cross section of circular casing at $\varphi=88^{\circ}$ at the design point. 
$v \quad$ absolute velocity $(\mathrm{m} / \mathrm{s})$

$w$ relative velocity $(\mathrm{m} / \mathrm{s})$

$\varphi \quad$ angular advancement (deg.)

$\theta \quad$ opening angles of volute side wall (deg.)

$\rho \quad$ fluid density $\left(\mathrm{kg} / \mathrm{m}^{3}\right)$

$\omega$ angular velocity $\left(\mathrm{s}^{-1}\right)$

\section{References}

Hutchinson, B.R. et al., 1994. Prediction of the threedimensional turbulent flow in centrifugal pump impellers,
CFD 94, CFD Society of Canada, Toronto, Ontario, June 1-3.

Majidi, K., 1997. Numerische Berechnung der Sekundärströmung in radialen Kreiselpumpen zur Feststofförderung, Ph.D. thesis, Technische Universität Berlin.

Majidi, K. and Siekmann, H.E., 1996. Numerische Untersuchung der Sekundärströmung in REA-Pumpen, Sektion C3-1, Pumpentagung Karlsruhe 96, 30. September bis 02. Oktober.

Stepanoff, A.J., 1949. Centrifugal and Axial Flow Pumps, John Wiley, New York.

TASCflow, 1995, User Documentation, Version 2.5. Theory Documentation. 


\section{ait \\ ENERGY MATERIALS}

M A N E Y publishing

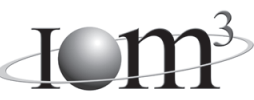

\section{Materials Science \& Engineering for Energy Systems}

Maney Publishing on behalf of the Institute of Materials, Minerals and Mining

The Institute of Materials, Minerals \& Mining

Economic and environmental factors are creating ever greater pressures for the efficient generation, transmission and use of energy. Materials developments are crucial to progress in all these areas: to innovation in design; to extending lifetime and maintenance intervals; and to successful operation in more demanding environments. Drawing together the broad community with interests in these areas, Energy Materials addresses materials needs in future energy generation, transmission, utilisation, conservation and storage. The journal covers thermal generation and gas turbines; renewable power (wind, wave, tidal, hydro, solar and geothermal); fuel cells (low and high temperature); materials issues relevant to biomass and biotechnology; nuclear power generation (fission and fusion); hydrogen generation and storage in the context of the 'hydrogen economy'; and the transmission and storage of the energy produced.

As well as publishing high-quality peer-reviewed research, Energy Materials promotes discussion of issues common to all sectors, through commissioned reviews and commentaries. The journal includes coverage of energy economics and policy, and broader social issues, since the political and legislative context influence research and investment decisions.

\section{CALL FOR PAPERS}

Contributions to the journal should be submitted online at http://ema.edmgr.com

To view the Notes for Contributors please visit: www.maney.co.uk/journals/notes/ema

Upon publication in 2006, this journal will be available via the Ingenta Connect journals service. To view free sample content online visit: www.ingentaconnect.com/content/maney

For further information please contact:

Maney Publishing UK

Tel: +44 (0)113 2497481 Fax: +44 (0)1132486983 Email: subscriptions@maney.co.uk

or

Maney Publishing North America

Tel (toll free): 8662975154 Fax: 6173546875 Email: maney@maneyusa.com

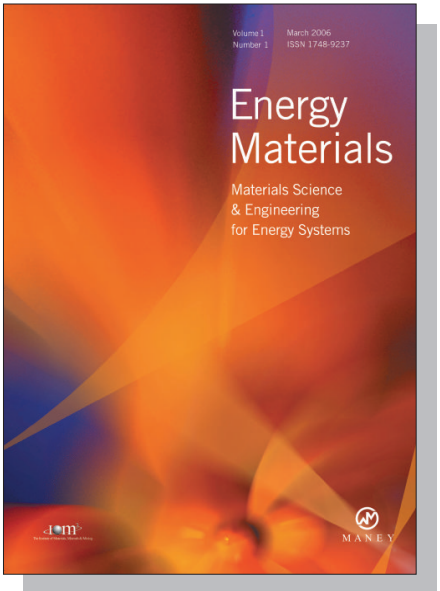

EDITORS

Dr Fujio Abe

NIMS, Japan

Dr John Hald, IPL-MPT, Technical University of Denmark, Denmark

Dr R Viswanathan, EPRI, USA

\section{SUBSCRIPTION INFORMATION}

Volume 1 (2006), 4 issues per year

Print ISSN: 1748-9237 Online ISSN: 1748-9245

Individual rate: $£ 76.00 / U S \$ 141.00$

Institutional rate: $£ 235.00 /$ US $\$ 435.00$

Online-only institutional rate: $£ 199.00 / U S \$ 367.00$

For special $\mathrm{IOM}^{3}$ member rates please email

subscriptions@maney.co.uk

\section{For further information or to subscribe online please visit www.maney.co.uk}



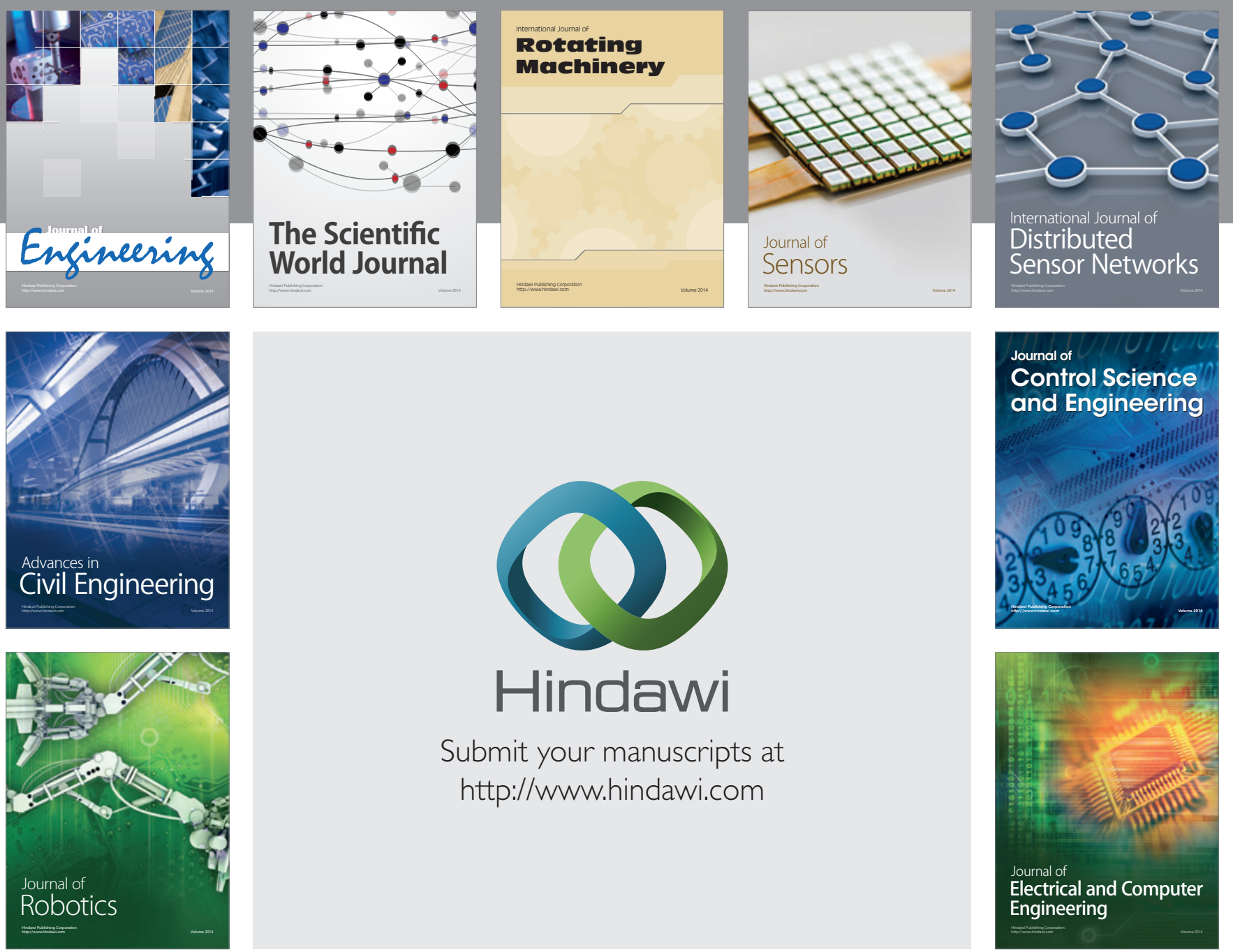

Submit your manuscripts at

http://www.hindawi.com
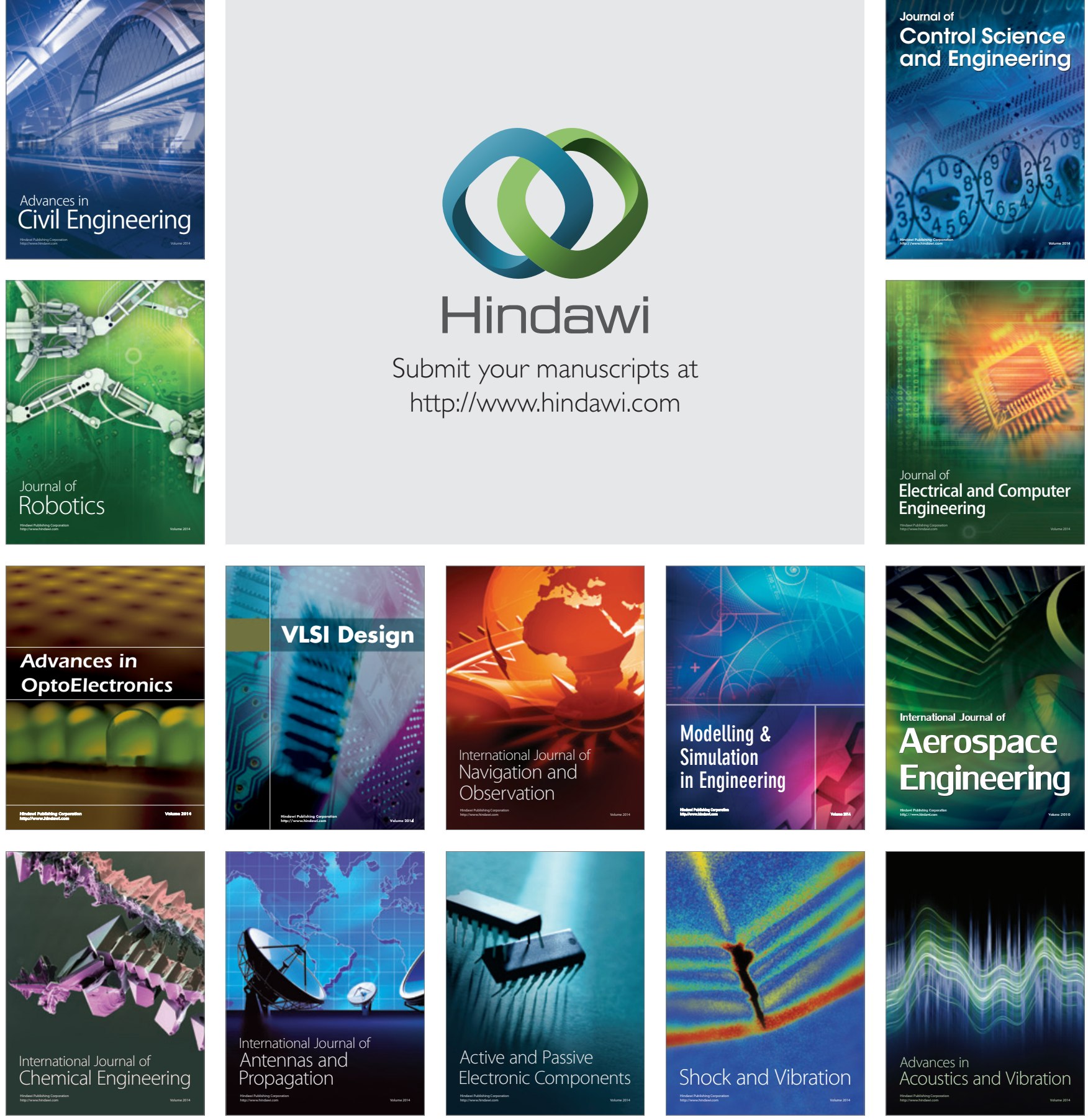